\title{
Estudo Comparativo entre aplicativos turísticos móveis
}

\section{Comparative study among mobile tourist applications}

\author{
Daniela Estaregue (ESTAREGUE. D.) ${ }^{*}$, \\ Berenice Santos Gonçalves (GONÇALVES, B. S.) ${ }^{* *}$ e \\ Marilia Matos Gonçalves (GONÇALVES, M. M.)
}

RESUMO - O turismo é um dos segmentos econômicos que tem apresentado crescimento no mundo dos negócios. Esse crescimento apoia-se em muitos fatores que se inter-relacionam, entre eles, estão os avanços tecnológicos (PAGE, 2011). A crescente demanda turística gera a necessidade de ampliação das fontes de informações. Sendo assim, as tecnologias têm favorecido a troca de conhecimento e possibilitando o intercâmbio de informações em tempo real apoiando de diferentes modos a atividade turística. A partir de aplicativos móveis pode-se ter conhecimento do local de destino com um maior grau de interação. Assim, este trabalho teve o objetivo de desenvolver um estudo comparativo, no ano de 2016, entre os aplicativos mais baixados em 2012 segundo documento apresentado pela Sociedade Estatal para a Gestão da Inovação e das Tecnologias Turísticas - SEGITTUR (ESPANHA, 2013). A partir deste estudo, identificou-se as principais ferramentas disponibilizadas por tais aplicativos e verificouse como estava sendo utilizado o potencial da tecnologia móvel. De um modo geral, constatou-se que a utilização desses aplicativos estava facilitando o processo da viagem, porém não foram encontradas ferramentas que ampliassem a experiência turística, ou seja, que combinassem a informação real com o conteúdo digital.

Palavras-chave: Turismo; Design de interface; Guia Turístico; Aplicativo móvel.

ABSTRACT - Tourism is one of the economic segments that has shown continuous growth in the business world. This growth is based on many factors that are interrelated among them there are the technological advances (PAGE, 2011). The growing tourist demand requires the increase of information sources. Therefore, the technologies have

\footnotetext{
* Formação: Graduação em Desenho Industrial pela Universidade Estadual Paulista (UNESP-Bauru), Mestrado em Design de Produção Visual pelo Instituto Superior de Artes, Design e Marketing (IADELisboa). Doutoranda do Programa Pós-Design da Universidade Federal de Santa Catarina (UFSC). Endereço físico para correspondência: CCE, Bloco A, sala 107 - Campus Reitor João David Ferreira Lima, s/n. CEP: 88040-900 - Florianópolis - Santa Catarina/SC - Brasil. E-mail: daniesta@ gmail.com

** Formação: Graduação em Artes Visuais e Mestrado em Artes Visuais pela Universidade Federal do Rio Grande do Sul (UFRGS) e Doutorado em Engenharia de Produção pela Universidade Federal de Santa Catarina (UFSC). Atividade profissional: Professora do Departamento de Expressão Gráfica da Universidade Federal de Santa Catarina (UFSC). Endereço físico para correspondência: CCE, Bloco A, sala 107 - Campus Reitor João David Ferreira Lima, s/n. CEP: 88040-900 - Florianópolis - Santa Catarina/SC - Brasil. E-mail: bereni.gon@gmail.com

*** Formação: Graduação em Educação Artística pela Universidade do Estado de Santa Catarina (UDESC) e em Design pela Universidade Federal de Santa Catarina (UFSC), Mestrado e Doutorado em Engenharia de Produção (UFSC). Atividade profissional: Professora do Departamento de Expressão Gráfica da Universidade Federal de Santa Catarina. Endereço físico para correspondência: CCE, Bloco A, sala 107 - Campus Reitor João David Ferreira Lima, s/n, CEP: 88040-900, Florianópolis - SC, Brasil. Email: marilinhamt@gmail.com
} 
promoted the exchange of knowledge and make possible to exchange information just in time and then supporting the tourist activity in several ways. Using mobile applications it is easier to know the target location with higher interaction. Thus, this paper had the objective of developing a comparative study in 2016 among the most downloaded applications in 2012 according to a report presented by State Society for Innovation Management and Tourism Technologies - SEGITTUR (ESPANHA, 2013). From this study, it was identified the main tools available by these applications and it was verified how the potential of mobile technology was being used. In general, it was found that the use of these applications make easier the travel process, but it was not found tools that amplify the tourism experience, in other words, that combine the real information with the digital content.

Key words: Tourism; Interface design; Tourist guide; Mobile app. 


\section{INTRODUÇÃO}

O turismo movimenta recursos financeiros diretos e indiretos contribuindo para o aumento do Produto Interno Bruto - PIB e para a melhoria da qualidade de vida da população. Neste sentido, Fernandes e Coelho (2011) afirmam que o setor tem evoluído, especialmente a partir da segunda metade do século XX, pois o setor é considerado o segmento de maior crescimento no mundo dos negócios. Esse crescimento apoia-se em muitos fatores que se inter-relacionam, entre eles, estão os avanços tecnológicos (PAGE, 2011). Segundo o Informe Destinos Turísticos Inteligentes (ESPANHA, 2015) o turista aparece mais informado (devido o acesso à internet e às redes sociais), mais exigente, autônomo (organiza sua própria viagem) e busca por produtos e serviços cada vez mais personalizados e completos.

Nesse contexto, as Tecnologias de Informação e Comunicação - TIC abrem novos horizontes para o setor do turismo. A tecnologia ubíqua, ou seja, que não possui mais lugar está presente em diferentes dispositivos e infiltra-se nas relações sociais. Assim, como em outros setores da economia, o turismo está evoluindo para se adaptar ao novo perfil do turista hiperconectado e interativo desenvolvendo e oferecendo produtos e serviços cada vez mais flexíveis, integrados e personalizados. Segundo o Informe Destinos Turísticos Inteligentes (ESPANHA, 2015) tal evolução no desenvolvimento de serviços e produtos só é possível sem a interrupção da tecnologia, em especial da internet e dos dispositos móveis, que estão impulsionando a geração de novos modelos de negócio no setor e que acompanham o visitante durante toda a sua jornada da viagem (antes, durante e depois). Tal informação é evidenciada por uma pesquisa realizada no mercado brasileiro que revelou que $73 \%$ das pessoas, que possuíam smartphones, não saiam de casa sem o seu aparelho e que para os jovens foi o item mais importante a ser levado frente a documentos e dinheiro (EXAME.COM, 2016).

Para Renato Pelissaro, diretor de marketing da PayPal na América Latina (BARIFOUSE, 2015), "hoje estamos vendo uma série de comportamentos do mundo analógico migrando para o digital, especialmente para o smartphone, porque a tecnologia oferece uma experiência melhor, neste caso, para o consumidor." 
Essa migração da informação também é observada no turismo que cada vez mais cria aplicativos para acompanhar o turista em todos os momentos de uma viagem.

Segundo Blanca Zayas, diretora de relações públicas da Tripadvisor Espanhola, as principais tendências do comportamento do consumidor são a acessibilidade móvel e a acessibilidade social (EMARKETING Y REPUTACIÓN ONLINE, 2012). Nesse sentido, empresas cada vez mais adicionam em seus aplicativos filtros de busca, comentários, opiniões, fotografias, reservas de voos e hotéis além de recursos de geolocalização para indicar lugares de interesse, hotéis ou restaurantes para os turistas em suas proximidades e integração com as redes sociais, tudo embasado na conexão com a internet, com a finalidade de cada vez mais melhorar essa acessibilidade móvel e social comentada por Zayas (EMARKETING Y REPUTACIÓN ONLINE, 2012).

Diante do exposto, neste trabalho se propõe verificar as funcionalidades disponibilizadas em aplicativos de turismo - na categoria de guia de destino turístico para dispositivos móveis com a finalidade de perceber as principais ferramentas disponibilizadas por tais aplicaitvos e verificar como estava sendo explorado o potencial da tecnologia móvel no setor.

\section{TURISMO}

As Nações Unidas e a Organização Mundial do Turismo - OMT definem o turismo como:

O turismo é um fenômeno social, cultural e econômico, que envolve o movimento de pessoas para lugares fora do seu local de residência habitual, geralmente por prazer. (NAÇÕES UNIDAS e OMT, 2010, p. 1)

A partir dessa definição, pode-se observar que o turismo gera efeitos em seu entorno. Entre esses efeitos está a geração de bens e serviços que formam um conjunto de atividades econômicas, como: serviços de hospedagem; alimentação; transporte; agências de viagens; serviços culturais, esportivos, recreativos; comércio; interpretação e conservação do patrimônio histórico, cultural e natural (EL ESTUDIO SOBRE TIC Y TURISMO, 2016). Essas atividades que vão desde a organização da viagem até as 
lembranças/recordações geram expectativas, percepções e memórias nos turistas e criam a chamada experiência turística (SHENG; CHEN, 2013).

Uma pesquisa publicada na revista "Digital Tourism Think Tank" (NEUHOFER; BUHALIS, 2015) sobre a experiência turística relaciona as fases do turismo à TIC (FIGURA 1). Observando a relação entre a tecnologia e a experiência turistica (FIGURA 1) percebe-se que na fase "antes da viagem" o indivíduo está interessado em descobrir os principais e mais famosos atrativos turísticos de um local, mesmo que não seja de seu interese fazer esse tipo de turismo, pois tais informações o auxiliam na tomada de decisão. $\mathrm{Na}$ fase "durante a viagem" o turista procura por informações atualizadas sobre navegação, informações culturais, compartilha experiências, o que consequentemente reflete na fase do "depois da viagem", pois os compartilhamentos irão refletir as suas experiências e influenciarão as ações de outras pessoas. Essa relação das fases do turismo com a tecnologia faz com que o turista obtenha informações em qualquer lugar e a qualquer hora maximizando as possibilidades de novas formas de criar/intensificar as experiências. Neste processo, as TICs aparecem para apoiar os turistas em suas atividades o que significa dizer que a experiência turística não está mais restrita aos serviços de encontros presenciais, mas estendida a espaços virtuais. Isto posto, percebe-se o desafio de entender como a tecnologia pode ser utilizada como estímulo para criação de novos produtos e serviços e criar experiências de sucesso no setor (NEUHOFER; BUHALIS, 2015).

FIGURA 1 - RELAÇÃO ENTRE A TECNOLOGIA E A EXPERIÊNCIA TURÍSTICA

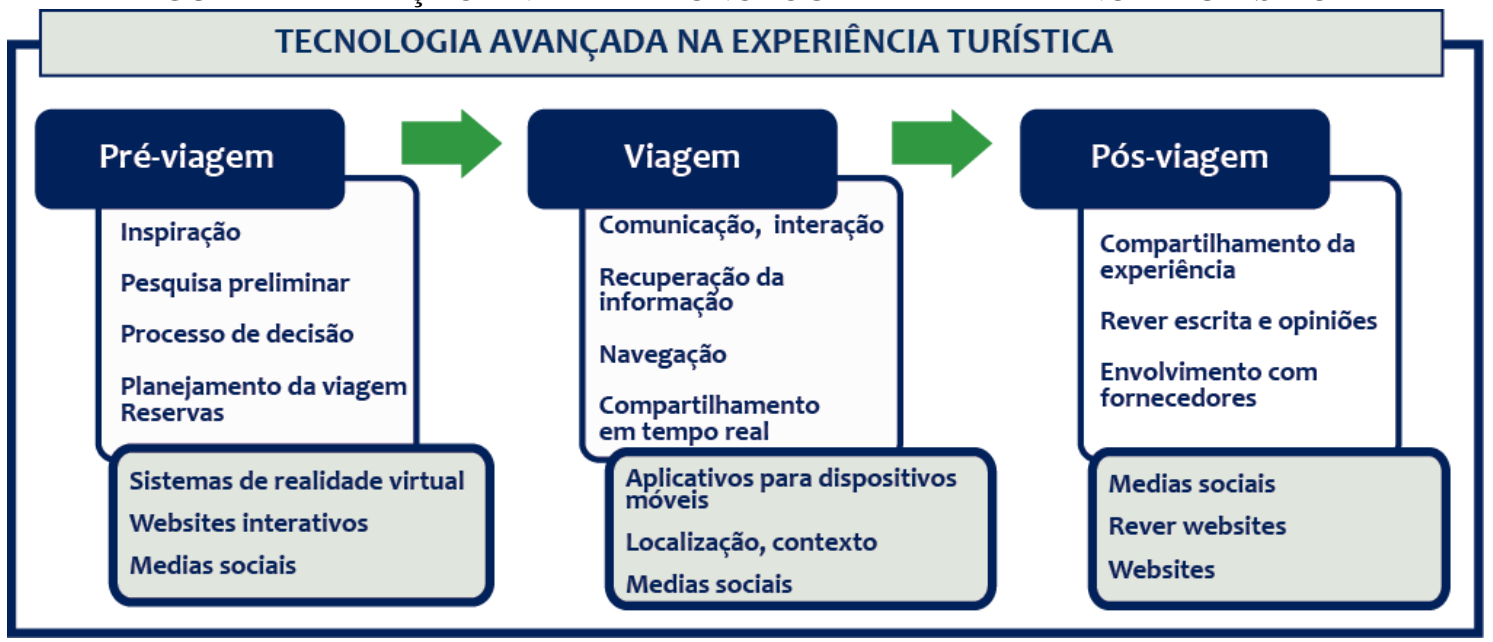

FONTE: Neuhofer e Buhalis (2015, p. 2). 


\subsection{O TURISMO E A TECNOLOGIA MÓVEL}

As TCIs mudaram o cenário turístico proporcionando o acesso à informação e a facilidade em estar em diversos lugares ao mesmo tempo. Juntamente com o avanço tecnológico aparece o crescimento do uso da internet que também auxiliou essa mudança de cenário encurtando consideravelmente o tempo de tomada de decisões. Segundo a World Travel and Tourism Council (WTTC, 2011) uma em cada cinco pessoas organiza seu feriado/viagem em menos de cinco dias antes de viajar. Este dado revela a autonomia do turista atual que tem o poder de planejar/organizar sua viagem para qualquer lugar no mundo a qualquer hora. Ainda segundo a WTTC (2011, p. 12):

\footnotetext{
Graças à pesquisa on-line, turistas de todas as idades também são muito mais informados sobre os produtos e serviços disponíveis quando eles tomam suas decisões de viagem. Eles personalizam seus proprios itinerários e pacotes, comparando preços e produtos [...] A tecnologia móvel levou isso a um passo adiante e os consumidores são capazes de pesquisar, reservar e revisar produtos em movimento.
}

Assim, nota-se o impacto da tecnologia móvel no turismo, pois a tecnologia móvel permite que as pessoas viajem tanto na internet e com a internet. Um estudo divulgado pela editora PANROTAS (2015) de como os viajantes brasileiros estavam planejando suas viagens mostra números significativos da presença dos turistas na internet além de evidenciar o acompanhamento da tecnologia por toda a fase do turismo, como comentado anteriormente (FIGURA 2).

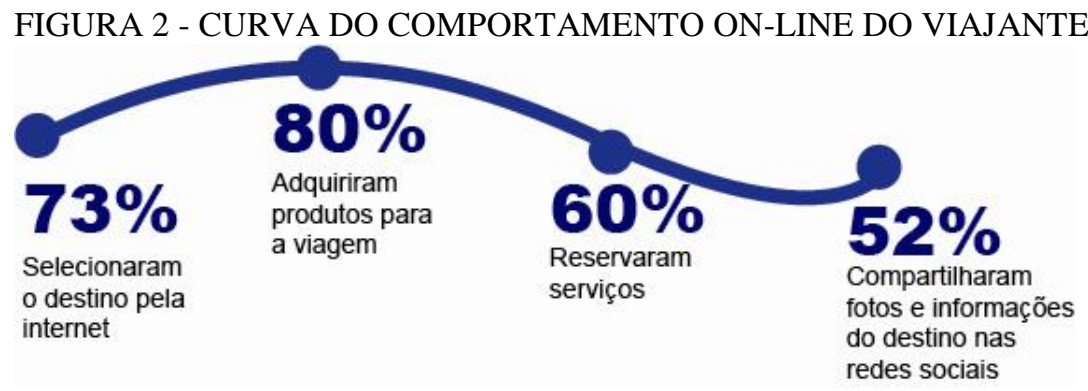

FONTE: Adaptado de PANROTAS (2015).

Tal informação revela a mudança de comportamento do consumidor na "indústria do turismo" (LAMSFUS et al., 2015). Por exemplo, as tecnologias móveis permitem um fluxo muito mais intenso de informação sem limites físicos além de serem 
altamente personalizadas tornando-se parte do ambiente, o que permite que o espaço se altere e seja controlado e transformado pela presença de atividades e de pessoas. (LAMSFUS et al., 2015). Os serviços móveis são capazes de adaptar a informação para as necessidades do viajante, uma vez que levam em consideração dados sobre as pessoas (por exemplo, localização do turista), os objetos e o seu entorno (LAMSFUS; ALZUA-SORZABAL, 2013). Na verdade, um aplicativo, por exemplo, pode ajudar os viajantes a encontrar atrações e planejar atividades, economizando tempo e dinheiro sem esforços adicionais (TUSSYADIAH; FESENMAIER, 2008).

Deste modo, o espaço físico de um modo geral tem sofrido alterações operadas por extensões, expansões e simulações resultantes da incorporação do desenvolvimento tecnológico. As tecnologias estão se apresentando como uma possibilidade de reconhecimento, conhecimento e produção de relações espaciais reais. Assim, não se pode deixar de destacar o papel importante da interface, pois é através dela que o sujeito se comunica com o sistema e quanto mais intuitiva e agradável ela for melhor será a comunicação entre sistema e sujeito.

\section{INTERFACE, MOBILIDADE E TECNOLOGIAS}

Em qualquer tipo de comunicação entre um homem e uma máquina, está implícito o conceito de interface - "quando utilizamos uma ferramenta existe sempre um espaço para que entremos em contato com ela" (ROYO, 2008, p. 49). Bonsiepe (2015, p. 12) complementa que "a interface revela o caráter de ferramenta dos objetos e o conteúdo comunicativo das informações”. Assim, a interface vai além da intersecção entre sistema e sujeito, ela é a conexão e a comunicação entre as duas partes, mesmo que existam diferenças ou incompatibilidades funcionais (SCHULENBURG, 2012).

A função da interface é facilitar e intermediar a relação interativa entre homem e máquina, garantindo que a atenção do sujeito esteja focada na tarefa que ele deseja executar. Isto implica que uma interface deve levar em conta:

A mobilidade (dinâmica), a navegação (orientação na exploração do espaço virtual), a conexão (ligação de hipertexto) e as questões da visualidade para relacionamento (cor, diagramação, elementos gráficos, imagens). A interface é a área em que as coisas interagem, é o meio de interação do usuário com 
um programa ou sistema operacional que emprega recursos gráficos (ícones e janelas) na edição de documentos, na utilização de programas, dispositivos e outros elementos (MOURA, 2003, p. 215).

Assim, pode-se considerar que a interface é um artefato digital que possibilita que o sujeito e o sistema se comuniquem sem a necessidade de conhecer linguagens de programação. Tal caracteristica permite que a interface funcione como uma ferramenta de comunicação e, por este motivo, deve apresentar certos requisitos como: facilidade de aprendizagem, simplicidade de uso, além de emitir clareza.

Santaella $(2008,2013)$ destaca que a internet e, conseguentemente a interface, potencialize a interseção do mundo real e os novos espaços virtuais (ciberespaços) devido à portabilidade conectada dos dispositos móveis, que concede ao ser humano o atributo da ubiquidade e possibilita encontros em contextos distintos. Isto posto, há cada vez mais a necessidade de compreender esta interseção, pois o espaço está sendo transformado por meio das interfaces tecnológicas. Ainda segundo Santaella (2008) as práticas de acesso propiciadas pelos dispositivos móveis conectadas ao Sistema de Posicionamento Global (GPS) fazem emergir um novo espaço de misturas entre o virtual (o ciberespaço) e os ambientes físicos em que o ser humano circula (SANTAELLA, 2008, p. 128). Assim, lugares e objetos passam a dialogar com dispositivos informacionais, enviando, coletando e processando dados. Tal conjunto de processos e tecnologias caracterizado pela emissão de informação digital a partir de lugares e objetos é conhecido como mídia locativa (SANTAELLA, 2008; LEMOS, 2011).

Lemos (2011, p. 207) define o termo mídia locativa como:

\begin{abstract}
Um conjunto de processos e tecnologias [que] se caracteriza por emissão de informação digital a partir de lugares/objetos. Esta informação é processada por artefatos sem fio, como GPS, telefones celulares, palms e laptops em redes Wi-Fi ou Wi-Max, Bluetooth, ou etiquetas de identificação por meio de rádio frequiência (RFID). As mídias locativas são utilizadas para agregar conteúdo digital a uma localidade, servindo para funções de monitoramento, vigilância, mapeamento, geoprocessamento (GIS), localização, anotação ou jogos. Dessa forma, os lugares e objetos passam a dialogar com dispositivos informacionais, enviando, coletando e processando dados a partir de uma relação estreita entre informação digital, localização e artefatos digitais móveis.
\end{abstract}

As mídias locativas se acessadas apenas no espaço virtual vão gerar comunicação sobre o espaço, sem a experiência do espaço real. Com implantação das 
midias locativas, os espaços fisico, social, mental e digital podem ser ligados uns aos outros, transformando a experiência e caracterizando os novos espaços públicos.

As aplicações das mídias locativas desdobram-se em "realidade aumentada móvel, mapeamento e monitoramento do movimento, geotags, anotação urbana" (LEMOS, 2011, p. 209), utilizando-se de uma ou mais destas propriedades. Assim, o recurso da realidade aumentada, através de um dispositivo móvel pode proporcionar informações extras a respeito do local e da região onde o turista se encontra com o auxílio do GPS e a rede sem fio. Ou ainda, com o auxilio das geotags informar aos turistas os hotéis / restaurantes / pontos turísticos próximos à sua localização, trazendo tais informações no próprio mapa do dispositivo móvel, fornecendo hiperlinks que conectam ao website do local com fotos, informações de preço, distância e entre outras informações. Tais funcionalidades emergem do espírito de buscar e criar experiências mais ricas entre as pessoas e os espaços contribuindo com o exercício de recreação de inteligência espacial e sinestésica para as pessoas (LEMOS, 2011, p. 228).

\section{METODOLOGIA}

Considerando os objetivos do presente artigo, foi utilizado o método comparativo para investigar as funcionalidades dos aplicativos turísticos. De acordo com Gil (2008) o método comparativo procede pela investigação de fenômenos ou fatos, com vistas a ressaltar as diferenças e similaridades entre eles.

Para isso, utilizou-se como base um ranking apresentado pela Sociedade Estatal para a Gestão da Inovação e das Tecnologias Turísticas da Espanha - SEGITTUR (ESPANHA, 2013) dos apps mais baixados em 2012. O ranking está dividido em categorias de apps turísticos, a categoria escolhida para este artigo foi o de "guia de destino turístico" o qual apresenta uma lista dos 20 apps mais baixados em 2012. Dos 20 apps foram selecionados os que possuíam mais de 1.000 .000 de downloads para o estudo comparativo. Assim, são eles: Lonely Planet, Visit Korea, Tripwolf e Tripadvisor.

Após a seleção dos apps eleitos realizou-se uma pesquisa sucinta para obter maiores informações do aplicativo, iniciou-se a instalação e posteriormente a navegação 
dos mesmos, elaborou-se uma descrição das funcionalidades o que serviu de base para elaboração de uma lista de requisitos para o desenvolvimento de um quadro comparativo. Os requisitos propostos para comparação foram: preço, tamanho, área geográfica, localização, plataforma, redes sociais, mapas, rotas, funcionalidades e filtros de busca.

A instalação dos apps foi efetuada em um smartphone com plataforma Android devido à disponibilidade do aparelho.

\section{DESCRIÇÃO DOS APLICATIVOS}

A seguir será apresentada a descrição dos quatro aplicativos selecionados para o estudo comparativo de modo individual, para posteriormente apresentar uma discussão dos resultados.

\subsection{LONELY PLANET}

Segundo o website da editora Lonely Planet (2016a) eles são a maior editora de guias de viagem do mundo. A marca nasceu em 1973 após uma viagem dos fundadores Tony e Maureen Wheeler, sendo a pioneira na publicação de guias e livros para viajantes (LONELY PLANET, 2016a). A partir de 2000, a marca de propriedade da BBC Worldwide lançou guias de bolsos com assuntos variados (LONELY PLANET, 2016a). Posteriormente, a Lonely Planet passou a oferecer mais de 650 livros e guias publicados em 14 idiomas, retratando mais de 150 países, uma revista de viagens mensal e ainda o canal de televisão Lonely Planet Television. Os guias da Lonely Planet foram os primeiros a ter versões eletrônicas para iPhone (LONELY PLANET, 2016a).

O Lonely Planet App estava na sua versão 1.0.5.228 para a plataforma Android. Ao abrir o app, inicialmente, aparecia uma tela com todas as opções (cerca de 50 guias de diferentes cidades). 


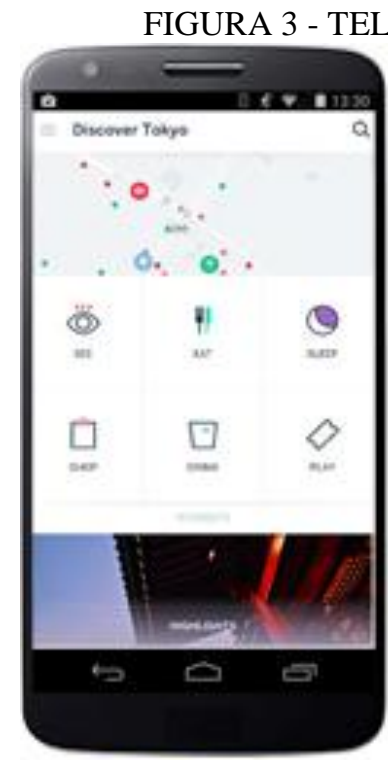

TELA PRINCIPAL

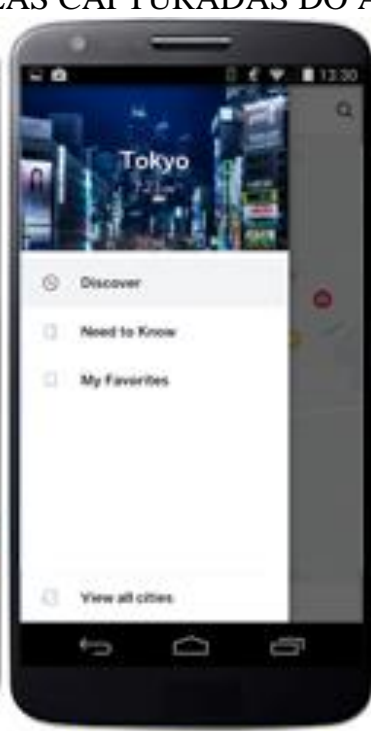

MENU SECUNDARIO

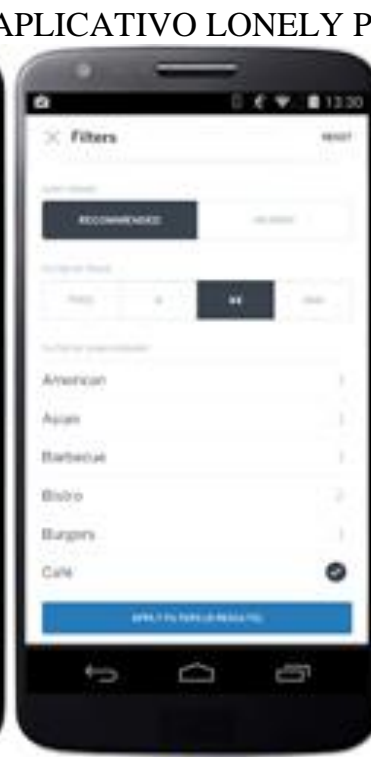

FILTROS

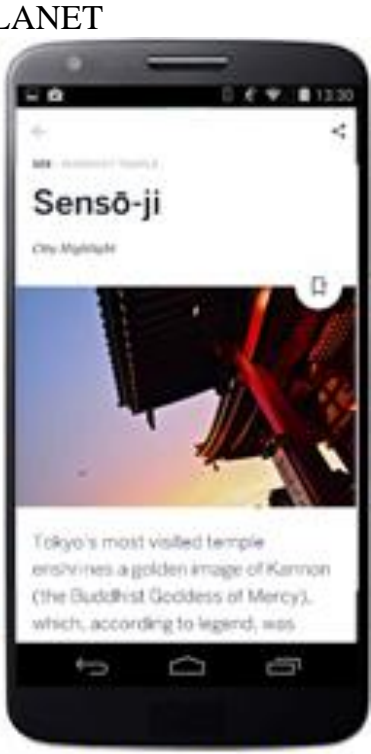

DETALHES DO LOCAL

FONTE: Lonely Planet (2016b).

Ao selecionar um determinado destino apareceram informações textuais sobre o local, opções de compartilhamento, fotos no caso de pontos turísticos, endereço, telefone, website, mapa, horário de funcionamento, preço e locais próximos. Cabe ressaltar que ao clicar nas opções "Ver" e "Entretenimento" os resultados textuais foram acompanhados de fotos dos locais como pano de fundo dos botões, tais fotos não se diferenciaram da foto única apresentada com a informação detalhada de cada ponto. Também foi possível selecionar o resultado a partir da eleição dos filtros, tais como: Recomendado / Locais Próximos / Preço / Subcategorias que variavam de acordo com a opção previamente selecionada. (FIGURA 3).

Destaca-se que todos os recursos descritos no aplicativo estavam sendo oferecidos gratuitamente.

\subsection{VISIT KOREA}

Visit Korea App foi criado pela Organização de Turismo da Coréia e fornece aos usuários informações sobre viagens na região. A versão do guia utilizada neste trabalho foi a versão 4.0.27 para Android. 


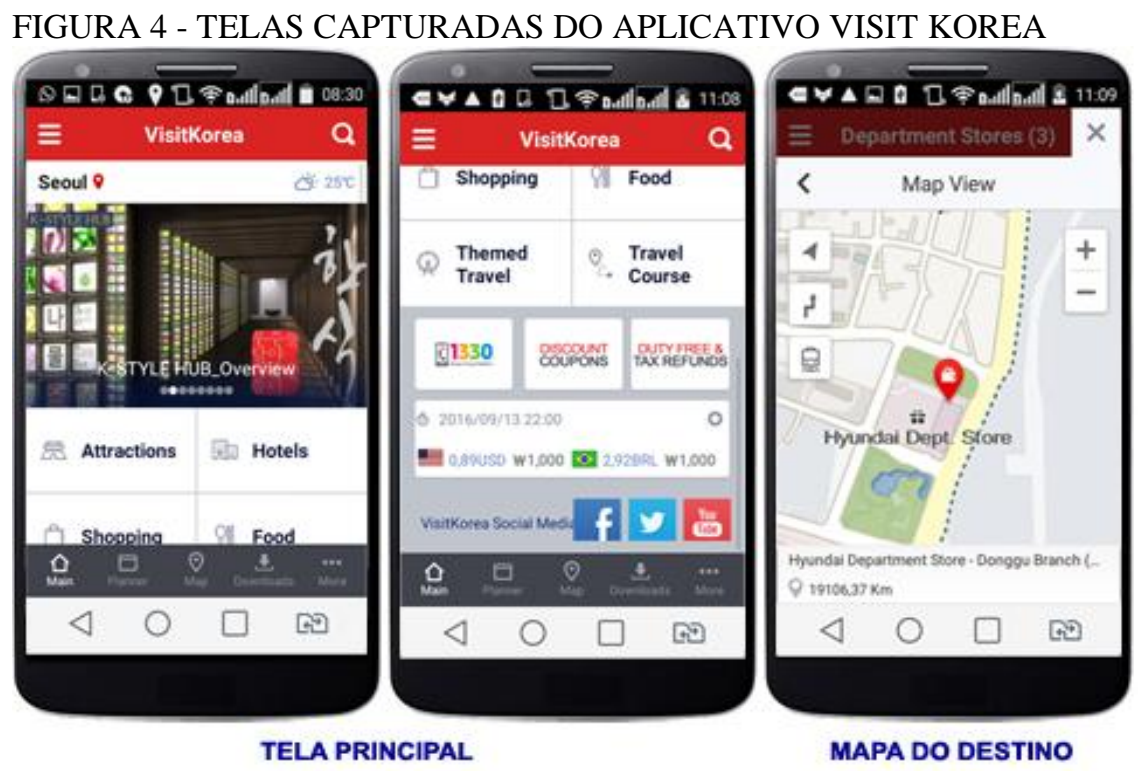

FONTE: Visit Korea (2016)

Ao abrir o aplicativo apareceu uma animação com oito fotos de pontos turísticos do país. Sob as fotos havia dois ícones, um de temperatura e outro de localização com o texto "todas as regiões" onde foi possível escolher a região do país a ser visitada. Ao selecionar o ícone da temperatura foi mostrado o mapa do país com suas respectivas temperaturas além da previsão do tempo para os próximos cinco dias. Abaixo das fotos foi exibido parte de um menu para filtrar as informações, sendo elas: Atrações / Hotéis / Compras / Comida / Turismo temático / Percurso de viagem. Em todas essas opções houve filtros que variavam de acordo com a opção, sendo apenas um filtro comum a todos - intitulado: "Recomendado para você" - onde foi solicitado informações sobre o usuário (idade, país de origem e sexo). Além do menu havia um botão chamado "Linha direta" que fazia um link direto com uma linha de turismo que suportava quatro idiomas, funcionava 24 horas além de ser gratuito. Ao lado do botão "Linha direta" havia outro botão, o "Cupom de descontos" que deu acesso a uma lista de cupons de descontos separados por: Categorias / Data / Ordem alfabética / Meses do ano. Ao escolher um dos cupons era mostrada uma foto do produto/serviço/local, um botão para localização no mapa e a opção de fazer download do cupom de oferta (FIGURA 4). Ainda ao lado dos botões "Linha direta" e "Cupom de descontos" havia o botão "Dutty Free" e "Reembolso de Impostos", que ao serem selecionados não trouxeram informações adicionais. Abaixo dos três botões havia informações sobre a conversão da 
moeda e os canais das redes sociais onde o Visit Korea se encontrava, como: Facebook, Twitter, Youtube (FIGURA 4).

Ainda na tela principal, um menu global ficava sempre visível com as opções: Principal / Planejador / Mapa / Downloads / Mais. Na opção "Mais" pôde-se fazer um cadastro no app, além das opções: Notificação inteligente / FAQ / Linha direta / Mais informações sobre o aplicativo. Na opção "Planejador" apareceram abas com as opções: Recomendado / Popular / Meu. Nas opções "Recomendado" e "Popular" apareceram filtros, como: Região / Período de permanência no local / campo para se digitar palavras-chave. A opção "Meu" também era utilizada para cadastro no aplicativo. Mesmo que se optasse por não filtrar as informações no Planejador apareceu uma lista de locais a serem visitados com a informação da quantidade de dias necessários para se conhecer o local.

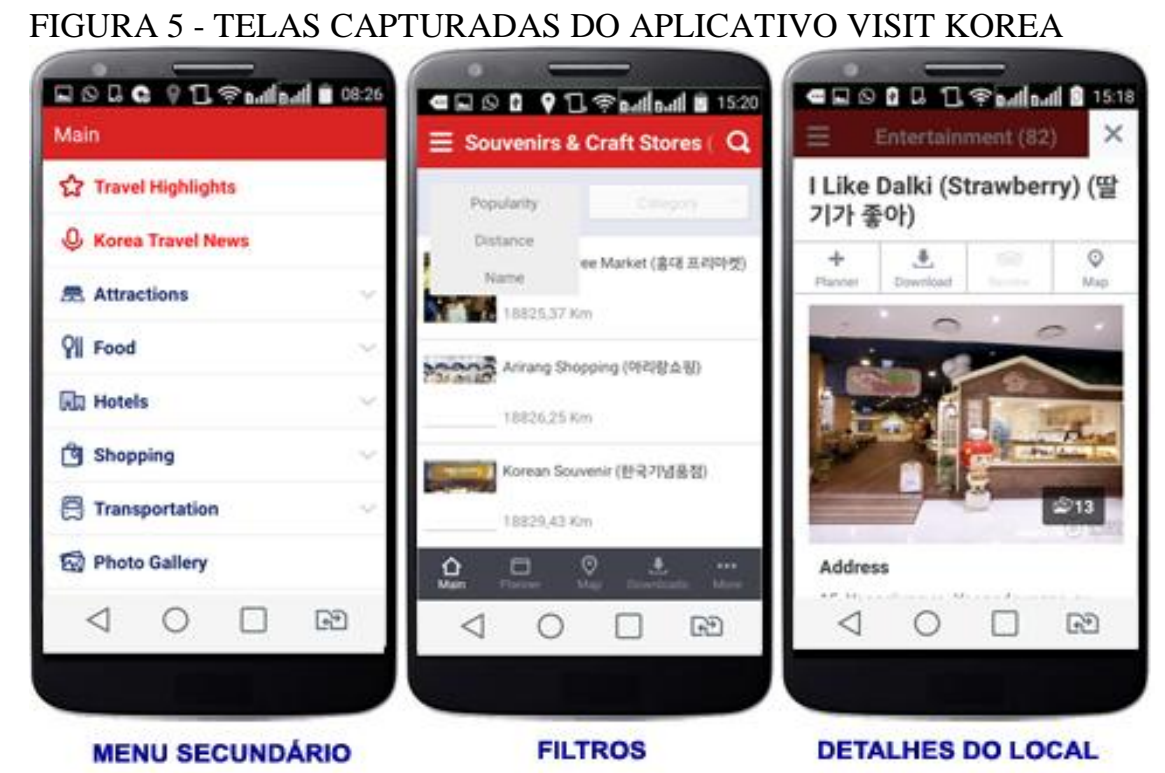

FONTE: VisitKorea (2016)

Nos detalhes de qualquer ponto turístico sempre aparecia uma foto do local e um ícone que levava a visualização de mais fotos e um menu com as opções: Planejador / Download / Comentários (que redirecionava ao website do Tripadvisor para se visualizar os comentários e críticas a respeito do local) / Mapa. Na opção mapa, havia a possibilidade de traçar rotas. Se escolhia um ponto de partida e destino, com a possibilidade de traçar rotas a partir de três filtros: transporte público, taxi ou a pé. Nos detalhes do ponto turístico havia informação completa sobre o local além da informação 
de como chegar ao destino separando a informação por tipo de transporte (trem, ônibus, táxi) além do tempo de viagem para se chegar ao local, se havia opção de carrinhos de bebê, imagens adicionais do Flickr Images e dois comentários mais recentes retirados do Tripadvisor, entre outras informações (FIGURA 5 acima).

Todos os recursos descritos acima e o aplicativo estavam sendo oferecidos gratuitamente.

\subsection{TRIPWOLF}

Segundo o guia de viagem Tripwolf (2016a) o app estava combinando dicas de viagens de escritores profissionais da área com informações de viagens, experiências e comentários a partir de uma comunidade mundial de milhares de viajantes.

A versão do guia de viagem Tripwolf utilizada neste trabalho foi a versão 4.8.0 para a plataforma Android. Ao abrir pela primeira vez o app ele apresentava uma pequena animação destacando os pontos fortes do aplicativo, como os mais de 600 guias disponíveis além das opções de planejar a viagem, imprimir roteiros ou usá-los off-line. Nos demais acessos se abria uma tela para aquisição de guias de cidades e países além da opção de adquirir ofertas especiais com dois tipos de pacotes: um com acesso ilimitado e outro com guias de 10 cidades. O valor dos guias de cidades e países variava de acordo com o local. Para o guia do Brasil, por exemplo, o valor era de $\mathrm{R} \$$ 22,42, para o da cidade de Florianópolis era de R\$3,90 para o do Rio de Janeiro R\$ 5,99. Após a aquisição de um guia era necessário fazer um cadastro. O app possibilitava o uso em até três dispositivos diferentes com a opção de baixar o guia para uso off-line.

Ao abrir o guia apareceu uma foto panorâmica da cidade, o horário local, botões de busca, mapa e uma opção para o download do guia (para se fazer uso off-line), tudo na parte superior direita da tela. Ao selecionar a opção mapa, apareceu o mapa da cidade com a opção "Locais próximos" onde se escolhia a distância do que se desejava procurar e a opção de filtro por três grandes áreas: Trens, Ônibus, Bonde / Necessidades diárias / Emergência. Cada uma com subdivisões específicas (FIGURA 6). 


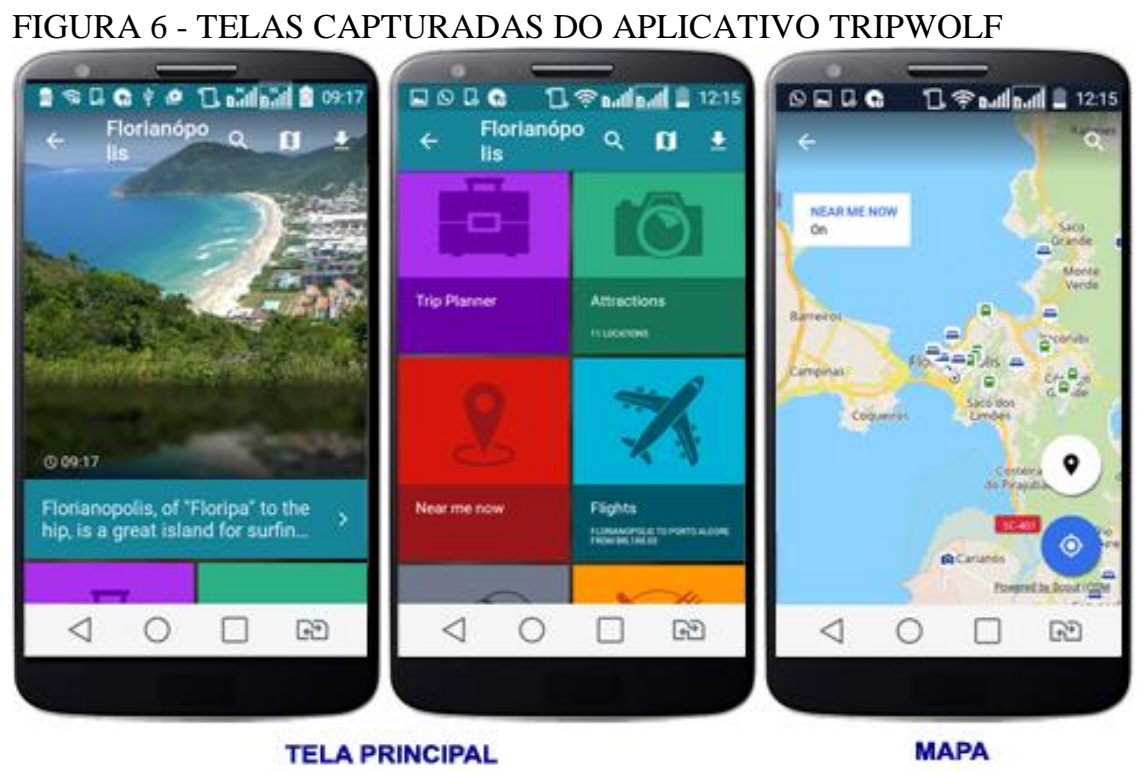

FONTE: Tripwolf (2016b)

Ao deslizar a tela principal ainda se tinha o conteúdo separado por filtros, como: Planejar a Viagem (funcionando como uma pasta de favoritos) / Locais Próximos / Atrações / Voos / Acomodações / Gastronomia / Shopping / Vida Noturna.

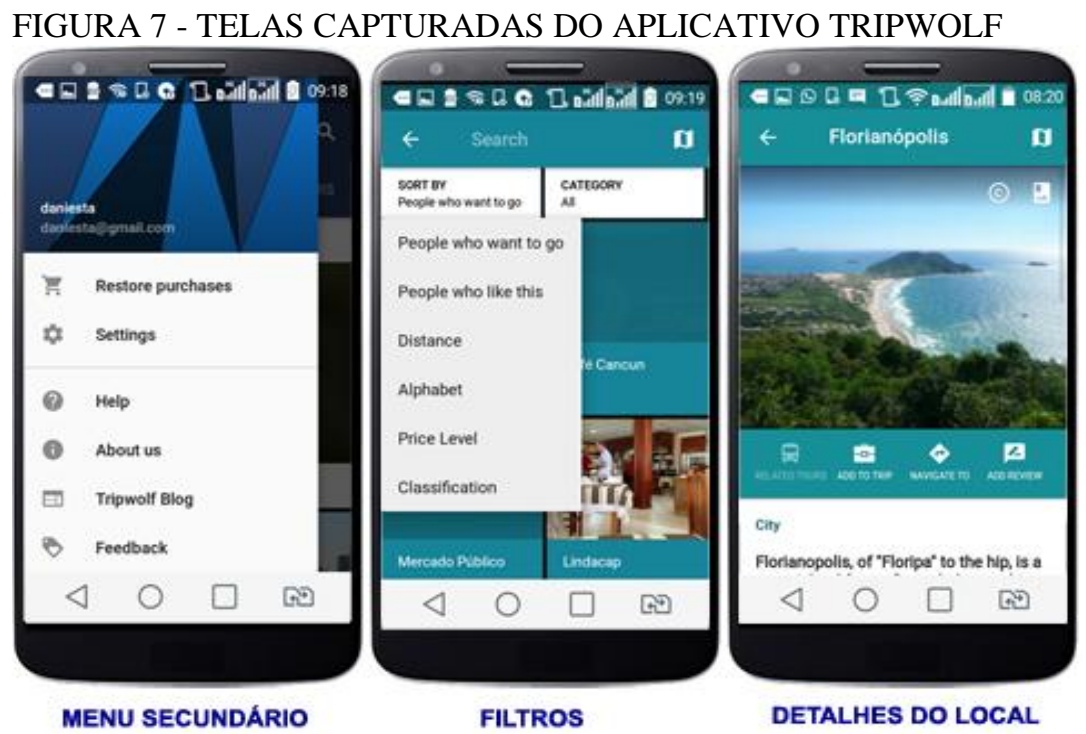

FONTE: Tripwolf (2016b)

Ainda na tela principal apareceram duas linhas de texto com informações sobre a cidade e que levava para uma outra tela com opção de visualizar mais fotos da cidade. Logo abaixo das fotos se tinha um menu com as opções: Passeios relacionados / Adicionar pontos / Ir para / Adicionar comentários. Abaixo do menu houve: Texto 
resumido sobre a cidade ou o local selecionado / Link para informações adicionais no wikipedia ou website / Curiosidades / Telefone / Endereço / Preço / Horário de funcionamento / Feedback. No caso da cidade apareceram informações sobre a população, língua, área e DDD.

No menu secundário teve-se as opções que podem ser observadas na Figura 7 acima.

\subsection{TRIPADVISOR}

A TripAdvisor Inc. gerencia e opera sites sob 24 outras marcas do setor de mídia relacionada a viagens. Os sites formam a maior comunidade de viagens do mundo e operam em 48 mercados (TRIPADVISOR, 2016a).

A versão do aplicativo Tripadvisor utilizada no estudo foi à versão 17.4 para a plataforma Android. Ao abrir o app apareceu um campo de busca e logo abaixo um menu global com as opções: Hotéis / Restaurantes / Atividades / Voo. Em cada uma das opções foi possível filtrar a informação por: Data (quando fosse o caso) / Distância / Localização / Pontuação do Viajante / Recursos do local entre outros que variava de acordo com a opção selecionada. Nesta tela não era preciso ter pesquisado um destino específico, podendo-se fazer buscas a partir de sua localização atual ou digitar o local. Abaixo do menu global era apresentado um menu secundário com as opções: Perto de Mim / Notificações / Favoritos / Reservas / Cidades Baixadas / Rascunhos de Avaliações / Fórum / Fazer uma Avaliação / Adicionar Fotos / Ferramentas de viagem / Central de ajuda / Feedback (link para email) / Configuração. Na opção "Perto de Mim" se tinha as opções de escolher os seguintes filtros: Restaurantes / O que Fazer / Hotéis / Sugestões. Na opção "Fórum" se tinha a opção de filtros por "Destinos" ou "Temas", na opção "Fazer uma Avaliação" colocava-se a pontuação do local com uma escala likert, o mês da visita, o tipo da visita e a descrição da avaliação, com opção de acrescentar imagens. Na opção "Ferramentas de viagem" sugeriam-se aplicativos gratuitos relacionados à viagem e na opção "Central de Ajuda" tinha-se a opção de Suporte Técnico / Diretrizes - que funcionava como um manual de instruções / Recursos do site / Comunidade. A diferença entre Diretrizes e recursos do site não ficaram muito claras. 


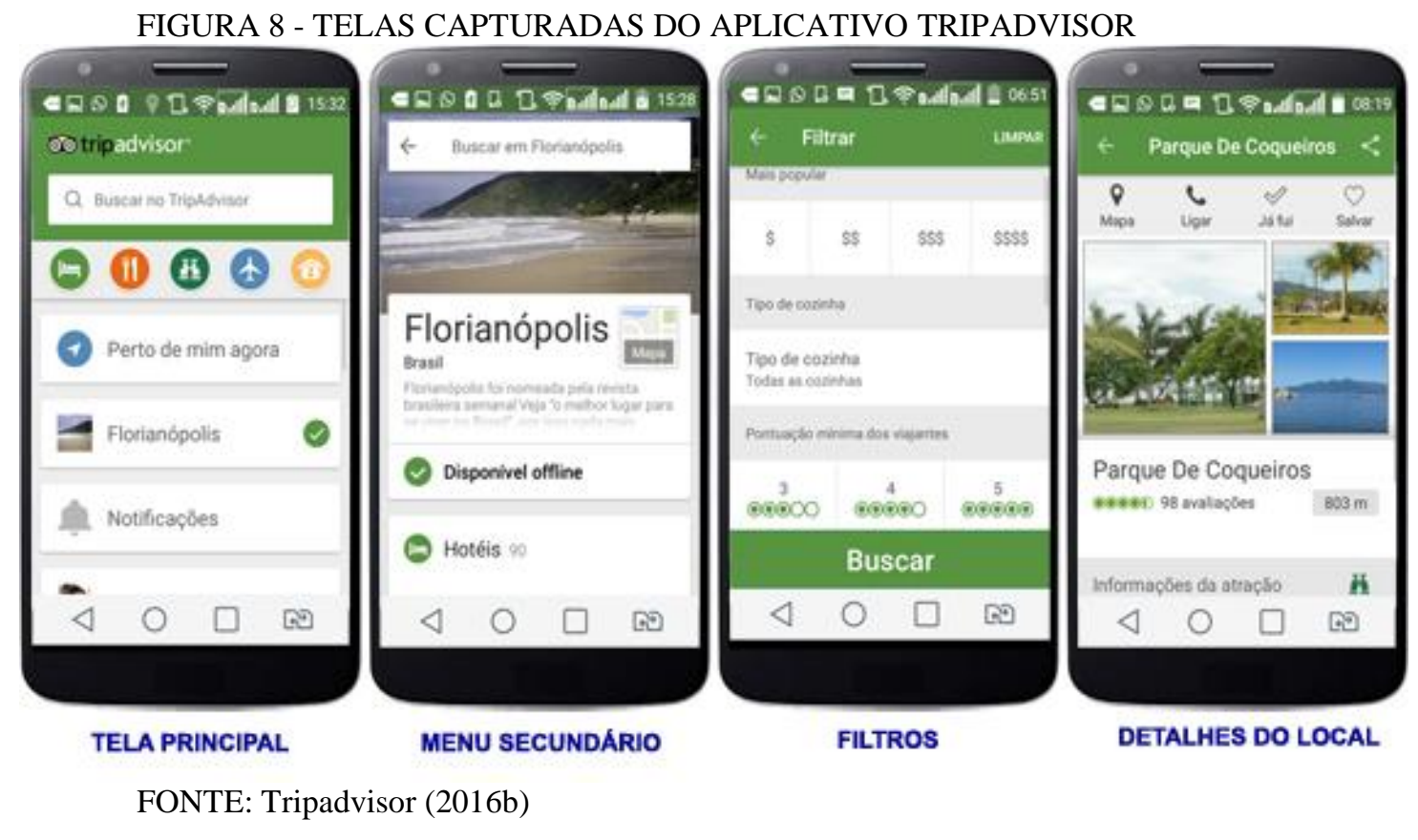

Quando se acessava o guia de uma determinada cidade o app mostrava uma foto local, com um resumo sobre a cidade, um link para o mapa e as mesmas opções do menu global com o acréscimo da opção Fórum / Trilha Sonora (com o Google Play Music) / Favoritos / Fazer uma Avaliação / Lista com as cidades mais visitadas nas proximidades. Na opção "O que Fazer", ao listar as atividades, havia a opção de se fazer reservas de passeios. Nos detalhes de qualquer tipo de destino turístico da cidade eram apresentadas três fotos do local, a avaliação, a distância a que se estava dela, uma pequena descrição, horários de funcionamento - quando fosse o caso, link para o Uber, Comentários e um menu com as opções de ver a localização no mapa, ligar quando fosse o caso, marcar o local como já visitado e salvar. Além das opções de compartilhamento.

\section{RESULTADOS}

Primeiro verificou-se informações básicas sobre os aplicativos, como: preço, tamanho, plataforma e área geográfica dos quatro aplicativos, como podem ser vistos na Figura 9. 


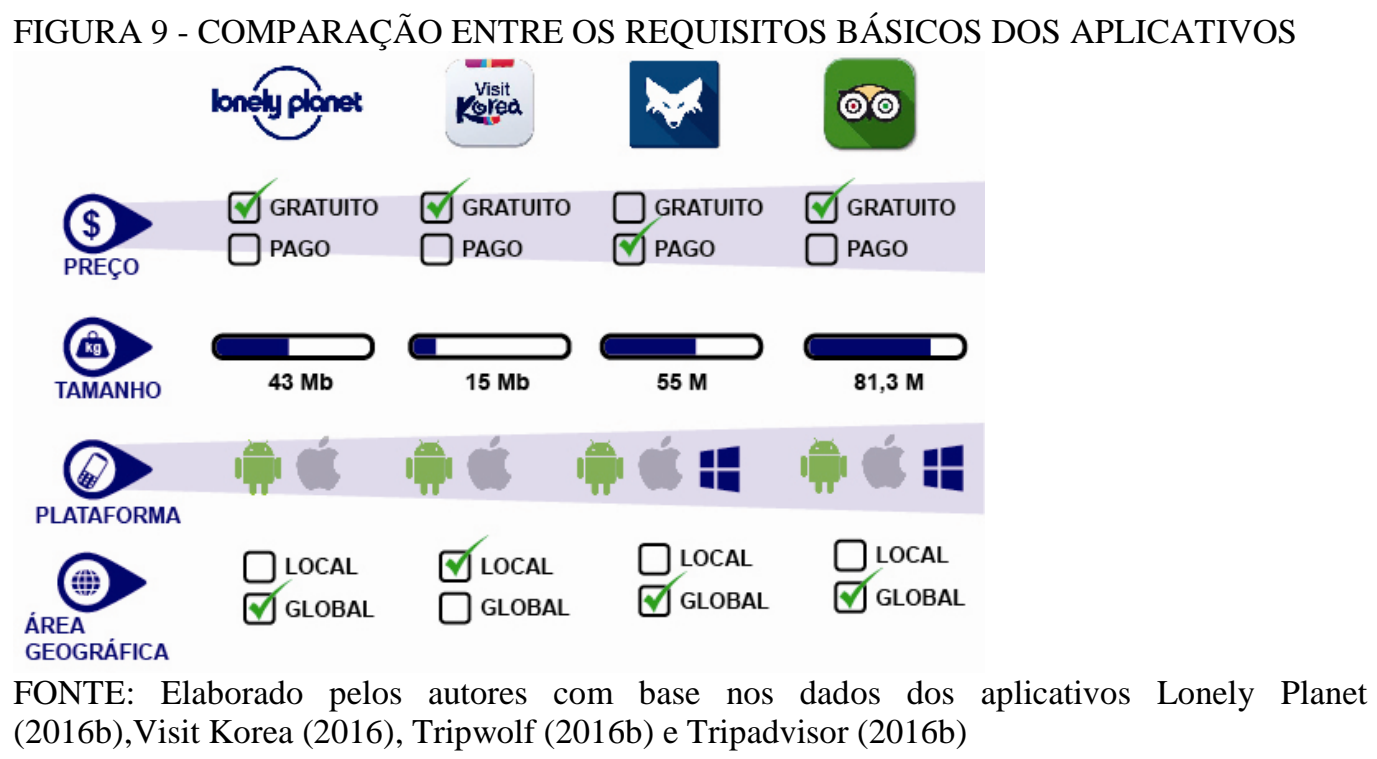

Como se pôde observar todos os apps eram gratuitos com exceção do Tripwolf. Na verdade o app Tripwolf era gratuito, mas seus guias eram pagos. Assim, se não se adquirisse algum guia o aplicativo ficava vazio o que impossibilitava a navegação.

Com relação ao tamanho inicial do arquivo o mais leve foi o Visit Korea seguido pelos Lonely Planet e Tripwolf. O Tripadvisor foi o mais pesado entre os quatro aplicativos. Colocou-se o tamanho inicial dos aplicativos, pois os tamanhos eram alterados de acordo com o uso. Os apps que acoplavam o mapa no aplicativo foram o Visit Korea e o Tripadvisor, os demais necessitavam fazer o download. Todos os apps estavam disponíveis para Android e IOS, mas somente o Tripwolf e o Tripadvisor estavam disponíveis também em Windows Phone. O único app que se limitava a uma região foi o Visit Korea, pois diferentemente dos demais apps ele foi desenvolvido por um órgão governamental, a Secretaria de Turismo da Coréia para divulgar o país. Já os demais aplicativos de viagens eram de empresas privadas.

$\mathrm{Na}$ figura 10 se compara os itens: mapas, rotas e redes sociais. Todos os apps disponibilizavam mapas dos destinos, mas apenas o Tripwolf e o Tripadvisor tinham a disponibilidade de acessá-los de modo off-line, sendo que para o Tripwolf era necessário salvar anteriormente o mapa e o Tripadvisor já vinha com o mapa acoplado. Ainda sobre os mapas considerou-se interessante notar que dois dos apps o acessavam via Google Maps, são eles, o Lonely Planet e o Tripadvisor. O Tripwolf disponibilizava o mapa via Scout e do Visit Korea não foi possível identificar a empresa fornecedora. 
FIGURA 10 - COMPARAÇÃO ENTRE OS APLICATIVOS, SOBRE OS ASPECTOS: MAPAS, ROTAS E REDES SOCIAIS

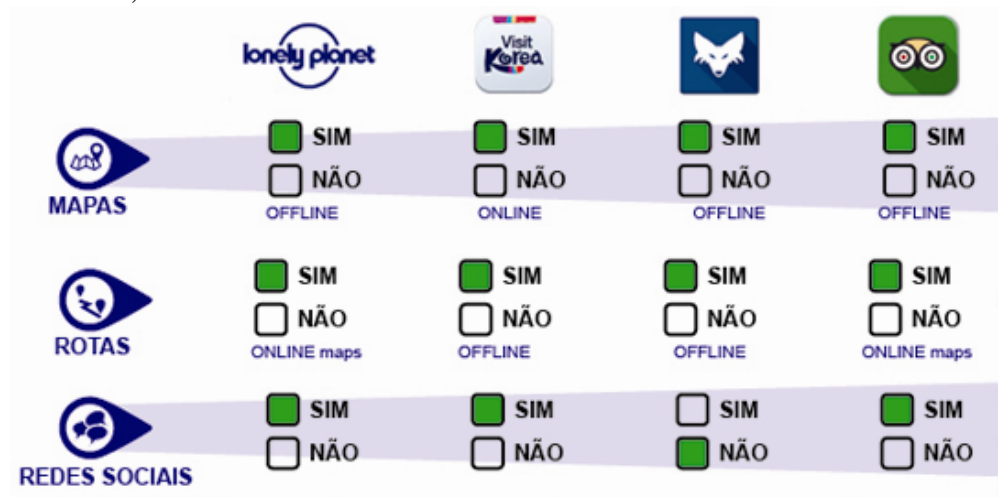

FONTE: Elaborado pelos autores com base nos dados dos aplicativos Lonely Planet (2016b),Visit Korea (2016), Tripwolf (2016b) e Tripadvisor (2016b)

Verificando a possibilidade de traçar rotas apenas dois dos apps possuíam a opção de salvá-las para o acesso off-line sendo eles os apps: Visit Korea e o Tripwolf (FIGURA 10). Os outros dois aplicativos possuíam a opção de Rotas, mas por meio do app do Google Maps que funcionava on-line. Uma funcionalidade diferenciada no app Visit Korea, na opção Traçar Rotas, é que além das opções de se traçar rotas a pé, de carro era possível traçar rotas a partir de transportes públicos como metrô, trens e ônibus e com isso obter os horários dos mesmos.

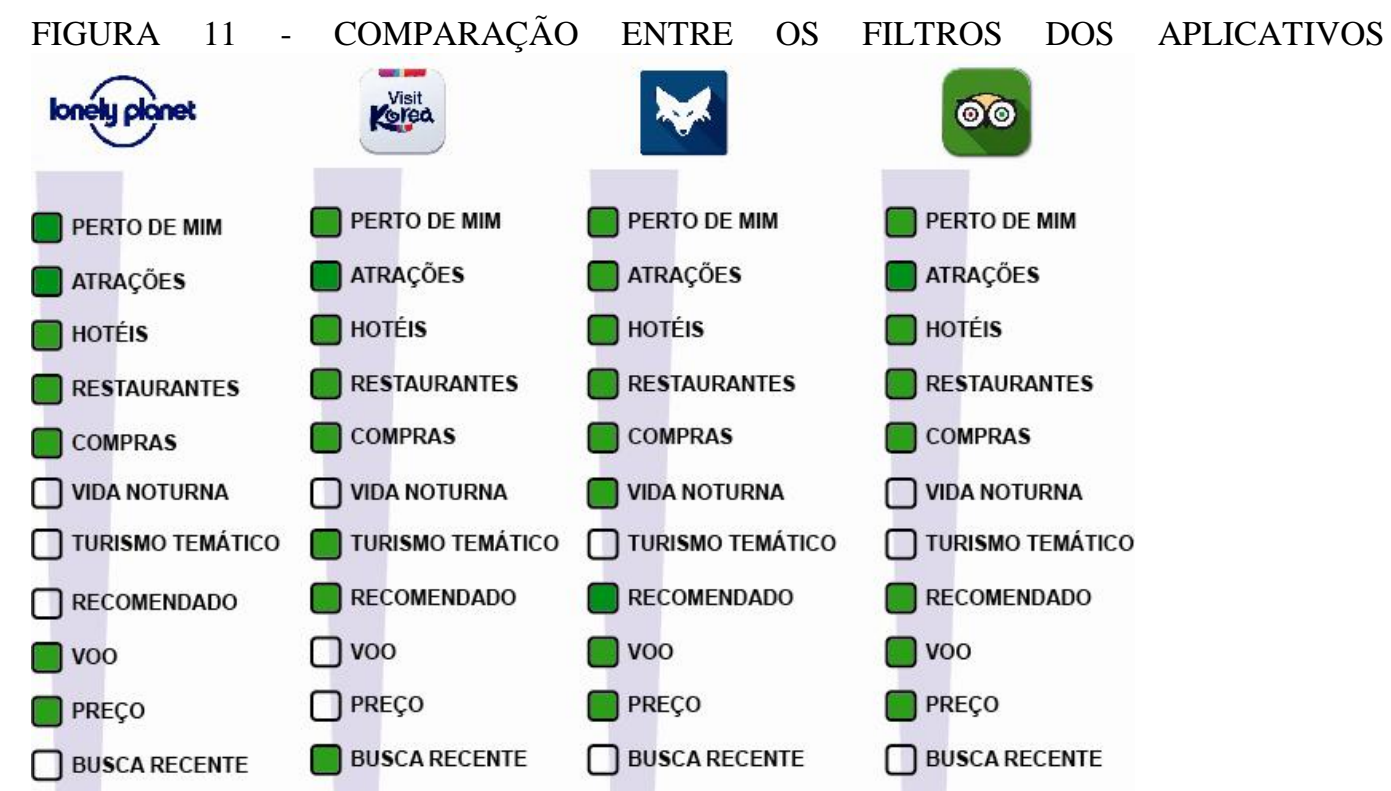

FONTE: Elaborado pelos autores com base nos dados dos aplicativos Lonely Planet (2016b),Visit Korea (2016), Tripwolf (2016b) e Tripadvisor (2016b) 
Sobre as funcionalidades de geolocalização básicas todos os apps possibilitaram a conexão com as redes sociais com exceção do Triwolf, talvez devido ao fator de seus guias serem pagos e por isso não permitirem o compartilhamento das informações e das fotos. Entretanto, as redes sociais, segundo Knop e Machado (2017), apresentam grande influência no processo de decisão de escolha de destinos turísticos por parte dos indivíduos, pois as pessoas são amplamente influenciadas pelos seus elos de amizade e aconselhamento, o que torna as redes sociais uma poderosa ferramenta a ser utilizada pelos aplicativos.

A respeito dos filtros de busca todos foram equivalentes quanto as opções de: procurar locais próximos ao usuário, atrações, hotéis, restaurantes, compras. Como pode ser observado na Figura 11 nos cinco primeiros itens listados. O Visit Korea tinha um diferencial no item "Perto de mim" que possibilitava uma notificação inteligente quando se estava chegando próximo do local além de oferecer dois outros itens que não foram encontrados nos outros apps, sendo eles: turismo temático e busca recente. O Lonely Planet possuía a busca por preço que também foi encontrado no Tripwolf e no TripAdvisor, mas nos dois últimos este filtro não foi tão evidente quanto no Lonely Planet.

A busca por voos não foi encontrada no app Visit Korea. O Tripwolf possuía um filtro que os outros apps não utilizavam, o "Vida Noturna" e, o Lonely Planet foi o único que não possibilitava ver as recomendações de outras pessoas que já haviam visitado o local. Ao observar os itens listados na Figura 11, percebeu-se que um aplicativo possuía sete itens de filtros, o Lonely Planet; o Tripadvisor e o Visit Korea possuíam oito filtros e o Tripwolf possuía nove itens.

A figura 12, mostra as funcionalidades de cada aplicativo. Visivelmente o que possuiu menor número de funcionalidades foi o Lonely Planet com apenas quatro das dezoitos funcionalidades listadas. O app Tripwolf apareceu com nove funcionalidades e os apps Visit Korea e Tripadvisor apareceram com 12 funcionalidades. Entre as funcionalidades comuns aos quatro aplicativos teve-se o "Mapa", "Rota" e "Favoritos". O app Lonely Planet além de não possibilitar a visualização de locais recomendados pelas pessoas também não possibilitava comentar e avaliar os destinos turisticos, sendo o app que possuiu menor integração com as redes sociais. Já o Tripadvisor se destacou 
nesse quesito porque além de comentar e avaliar o destino turistico permitia que se adicionassem fotos do local e a possibilidade de tirar dúvidas em um Fórum.

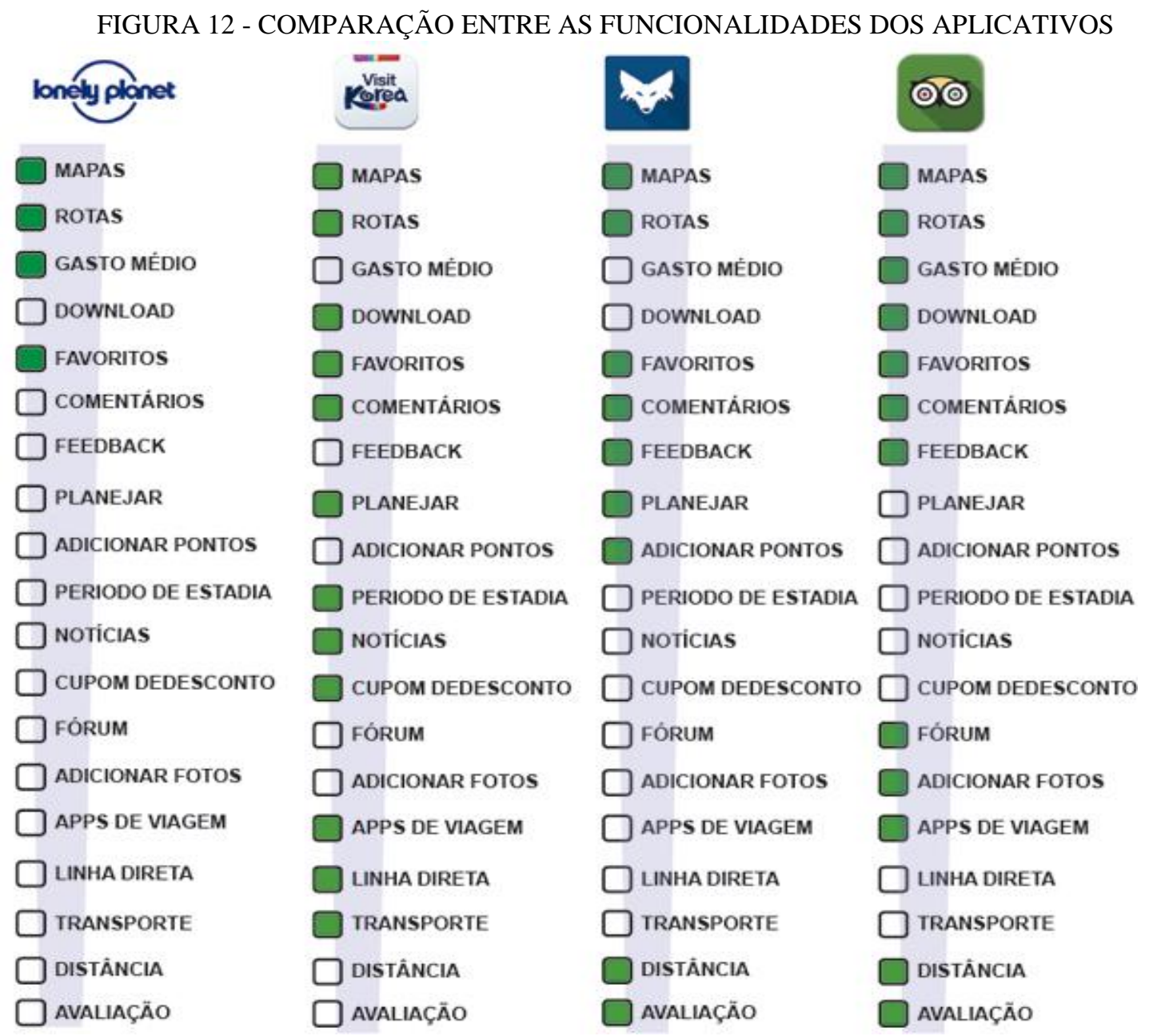

FONTE: Elaborado pelos autores com base nos dados dos aplicativos Lonely Planet (2016b),Visit Korea (2016), Tripwolf (2016b) e Tripadvisor (2016b)

Nesta lista de funcionalidades destacou-se o app Visit Korea com cinco funcionalidades que não foram encontradas nos outros apps, como: período de estadia, notícias, cupom de desconto, linha direta, dutty free e transporte. O Tripadvisor possuia apenas uma funcionalidade não comum aos demais apps, a funcionalidade: adicionar fotos. 


\subsection{DISCUSSÕES}

De certo modo os quatro aplicativos analisados vinham ao encontro com os interesses do perfil do turista atual, visto como mais indenpendente, pois todos os apps apresentaram informações essenciais para o gerenciamento de uma viagem, mas alguns se destacaram e ofereceram informações mais segmentadas e personlizadas que auxiliavam na cobertura de todo o percurso da viagem (antes, durante e depois).

Notou-se que a localização dos pontos turísticos, em todos os apps, se dava por mapas interativos e geolocalização que contextualizavam os filtros mais básicos como: atrações, restaurantes, hospedagens e compras. Tais filtros aliados à geolocalização permitiam o turista se situar no destino além de localizar pontos próximos de si. Neste sentido, o app Visit Korea foi o único que solicitava sempre a localização do usuário ao acessar o aplicativo e também foi o único dos aplicativos analisados que não salvava ou fazia o download do mapa para consulta ou impressão, pois sempre solicitava que o turista estivesse on-line. Tais limitações do app não permitiam a consulta dos locais quando o turista não tinha acesso à rede wi-fi ou similares, sendo um ponto negativo para o aplicativo. Porém uma funcionalidade diferenciada no app Visit Korea em relação aos demais foi a opção de escolha do meio de transporte ao traçar uma rota, por exemplo, os transportes públicos. Essa funcionalidade permitia ver o mapa do metrô e os horários dos ônibus, recurso útil para o turista que quisesse conhecer o destino aproximando-se da vida diária das pessoas que ali viviam.

Além dessas opções de localização, outro diferencial é que o turista tenha o máximo de informações possíveis e não apenas as que se referem a atrações turísticas, pois as informações gerais sobre as atrações são procuradas pelos turistas de massa. E, atualmente o turista quer se sentir inserido na cultura local buscando novas experiências em suas viagens, por isso, considera-se que informações como agenda cultural, costumes, festas, hospedagens alternativas são valiosas. Neste sentido, o app que forneceu tais conteúdos foi o VisitKorea, pois disponibilizava informações sobre transportes públicos, notícias sobre viagens no país, cupom de desconto, dicas recomendadas para o perfil cadastrado além de oferecer informações sobre estacionamento, carrinho de bebe, se era permitido fumantes e animais, assistência para 
estrangeiros, link para visualizar fotos no Flickr Images e comentários a respeito dos pontos no Tripadvisor website. Satisfazendo assim, um mercado mais segmentado.

Sobre as informações detalhadas dos destinos, como: resumo, local, horário e preço - estes foram equivalentes nos quatro aplicativos. Sendo que o Lonely Planet ofereceu grandes textos, com uma maior quantidade de dicas, como nos guias impressos, o que acabava se tornando uma leitura cansativa para este tipo de dispositivo, pois considera-se que o turista em movimento precisa de algo mais objetivo e direto.

Um aspecto marcante do app Tripwolf foi a inexistência de formas de compartilhamento das informações, que considerou-se ser um dos aspectos mais importantes para o turista compartilhar suas experiências. A publicação de fotos e comentários tem grande influencia nas pessoas e os amigos são uma das principais fontes de informação na fase da pré viagem (planejamento). Neste sentido o app Tripadvisor que se destacou na questão da interação, pois possibilitava variadas formas de interatividade como a de compartilhamento, comentários e a avaliação dos locais de forma fácil e rápida. Com este tipo de funcionalidade, o guia deixava de ser um serviço passivo, como é o guia impresso, e passava a ser uma fonte de informação ativa desde que o turista estivesse sempre conectado a internet. O que é reforçado pela afirmação de Blanca Zayas - relações públicas da Tripadvisor Espanhola - que as principais tendencias do comportamento do consumidor são a acessibilidade móvel e a acessibilidade social (EMARKETING Y REPUTACIÓN ONLINE, 2012).

Ainda a respeito da interação, a integração com outros websites também trazia benefícios aos apps possibilitando a cobertura de mais recursos, como a visualização de fotos e comentários no app Visit Korea, o link com o Uber no app Tripadvisor e a busca por hospedagem no app Tripwolf que fazia o link com o Booking.

Como pôde-se observar tais aplicativos, ao contrário dos guias impressos, possuíam uma dependência da internet para funcionarem em sua plenitude sendo que alguns possibilitavam a ferramenta de salvar ou fazer o download de mapas e outras informações, como foi descrito anteriormente. Sobre a interface gráfica todos foram equivalentes, com exceção do Tripwolf que possuiu um maior apelo devido à utilização das cores para separar o conteúdo em categorias e o uso de ícones maiores e mais chamativos. A navegação dos quatro aplicativos era intuitiva e aparentemente não 
apresentava grandes problemas, sendo que a navegação do app Lonely Planet foi menos ampla e menos profunda, talvez por apresentar uma menor quantidade de funcionalidades apesar de oferecer um rico conteúdo de informações textuais que precisariam ser repensandas para a aplicação em smartphone.

\section{CONSIDERAÇÕES FINAIS}

O objetivo deste trabalho foi observar as funcionalidades disponibilizadas em aplicativos de turismo com o propósito de perceber como o potencial da tecnologia móvel, neste tipo de aplicativo, estava sendo explorado.

Com a análise observou-se que o aplicativo com o maior número de informações diferenciadas foi o Visit Korea, pois possibilitava a leitura de notícias sobre turismo, disponibilizava cupons de descontos, recomendava passeios para o perfil cadastrado, além de possuir informações detalhadas do transporte público local, como horários e mapa.

O aplicativo que se destacou na questão de interação foi o Tripavisor, pois permitiu o compartilhamento de fotos e comentários além da possibilidade de avaliação dos locais visitados.

Dos quatro aplicativos analisados, o que possuiu mais informações detalhadas sobre os destinos foi o Lonely Planet, mas como destacado anteriormente essa quantidade de informação precisaria ser retrabalhada para o tipo de ferramenta a que se destinava, pois o grande volume de texto tornava a leitura cansativa e não eficaz para quem estava em mobilidade e precisava da informação de forma mais rápida.

Outro ponto a ser destacado, foi a parceria dos aplicativos com outras empresas que ampliavam a capacidade do app, pois passavam a oferecer mais recursos como foi o caso do Visit Korea com a visualização de fotos através do Flickr Images, o Tripwolf com a busca de locais para hospedagem através do Booking.com e o Tripadvisor com o Uber.

Como pôde ser verificado, a utilização desses guias facilitava o processo da viagem como um todo, principalmente no quesito mobilidade auxiliando os turistas a se localizarem em seus destinos. Contudo, notou-se que os aplicativos empregavam a tecnologia apenas para gerenciar as viagens e não para ampliar a experiência turistica 
fazendo uso da combinação da informação real com o conteúdo digital, como por exemplo, a realidade aumentada ou recursos de geolocalização através do GPS que possibilitariam outras formas de interação do que apenas situar o turista ou orientá-lo a navegar no seu destino.

Isto posto, percebeu-se que os aspectos encontrados em tais aplicativos buscavam oferecer uma gestão mais flexível para a viagem, sendo a mobilidade um componente importante neste tipo de dispositivo que ainda estava possuindo um potencial a ser explorado em algo mais atrativo para o perfil do atual turista.

Tal análise contribui para o desenvolvimento e gestão deste tipo de recurso na medida que expõe as funcionalidades comuns e as diferenciadas de cada aplicativo e, assim, auxilia no aprimoramento e/ou desenvolvimento de novos aplicativos com novas potencialidades para o setor turístico.

Os resultados encontrados não permitem generalizações, pois a comparação foi realizada em uma determinada categoria de guias turísticos móveis e num determinado período de tempo. Por este motivo seria pertinente, em estudos futuros, a verificação de diferenças de funcionalidades entre as demais categorias de guias turísticos além de se realizar um levantamento das funcionalidades de aplicativos móveis de outras áreas que pudessem ser aproveitados no setor do turismo.

\section{REFERÊNCIAS}

BARIFOUSE, R. Brasil 'supera média mundial' em compras por celular e tablet. 2015. Disponível em: <http://www.bbc.com/portuguese/noticias/2015/02/150226 _pagamentos_celular_rb>. Acesso em: 26/02/2016.

BONSIEPE, G. Design do Material do Digital. São Paulo: Blucher, 2015.

EL ESTUDIO SOBRE TIC Y TURISMO. Governo Espanhol: Ontsi, 07 abr. 2016.

EMARKETING Y REPUTACIÓN ONLINE. Las apps y su importancia en el turismo móvil. 2012. Disponível em:

$<$ http://www.turismoytecnologia.com/component/k2/item/1705-las-apps-y-suimportancia-en-el-turismo-movil>. Acesso em: 12/06/2016.

ESPANHA. Segittur. Ministerio de Energía, Turismo y Agenda Digital, y Adscrita A La Secretaría de Estado de Turismo (Org.). Estudio de Mercado de Apps Turísticas. Madrid: Segittur, 2013. 
ESPANHA. Segittur. Secretaria de Estado de Turismo (Org.). Informe destinos turísticos: construyendo el futuro. Madrid, 2015. 207 p.

EXAME.COM. Estatísticas de uso de celular no Brasil. 2016. Disponível em: $<$ http://exame.abril.com.br/negocios/dino/noticias/estatisticas-de-uso-de-celular-nobrasil.shtml>. Acesso em: 22/04/2016.

FERNANDES, I. P.; COELHO, M. F. Economia do turismo: teoria e prática. Rio de Janeiro: Elsevier, 2011.

GIL, A. C. Métodos e Técnicas de Pesquisa Social. 6. ed. São Paulo: Atlas, 2008.

KNOP, M. F. T.; MACHADO, J. S. Cibercultura e as influências das redes sociais virtuais na escolha de destinos turísticos: direcionamentos a partir de teorias sociológicas dos laços sociais. Turismo e Sociedade, [s. 1.], v. 10, n. 2, p. 1-20, 31 maio 2017. Universidade Federal do Parana. <http://dx.doi.org/10.5380/tes.v10i2.52528>. Disponível em: <http://revistas.ufpr.br/turismo/article/view/52528/32575>. Acesso em: 14/08/2017.

LAMSFUS, C.; ALZUA-SORZABAL, A. Theoretical framework for a tourism internet of things: Smart destinations. TourGUNE Jounal of tourism and human mobility, $p$. 15-21, 2013.

LAMSFUS, C.; MARTÍN, D.; ALZUA-SORZABAL, A.; TORRES-MANZANERA, E. Smart tourism destinations: An extended conception of smart cities focusing on human mobility. In: Information and Communication Technologies in Tourism, p. 363375, Germany: Springer, 2015.

LEMOS, A. (Org.). Mídia Locativa e territórios informacionais. In: SANTAELLA, L.; ARANTES, P. (Org.). Estéticas Tecnológicas: novos modos e sentir. São Paulo: Educ, 2008. p. 207-230.

LONELY PLANET (Org.). About us: Our story. 2016a. Disponível em: <http://www.lonelyplanet.com/about/story>. Acesso em: 02/05/2016. Site e como fazer com os apps?

LONELY PLANET (Org.). Guides by Lonely Planet. 2016b. Disponível em: <https://play.google.com/store/apps/details?id=com.lonelyplanet.guides\&hl=pt_BR>. Acesso em: 02/05/2016.

MOURA, M. O Design de Hipermídia. Tese (Doutorado em Comunicação e Seminótica) - Pontifícia Universidade Católica de São Paulo, São Paulo, 2003.

NAÇÕES UNIDAS E OMT. Departamento de Asuntos Económicos y Sociales (Org.). Recomendaciones internacionales para estadísticas de turismo 2008. Madrid/nueva York: Nações Unidas, 2010. 
NEUHOFER, B.; BUHALIS, D. Technology Enhanced Tourism Experiences ECHNOLOGY. The Digital Tourism Think Tank: Bournemouth University, 2015.

PAGE, S. Turismo e empreendedorismo. Rio de Janeiro: Elsevier, 2011.

PANROTAS (Brasil). Costumes do viajante brasileiro. Suplemento Especial Panrotas: tecnologia 2015. Mirandópolis/sp, 15 dez. 2015. p. 05-05. Disponível em: <http://www.panrotas.com.br/edicoes-digitais/detalhes/2016/12/tecnologia-jp1196_70.html>. Acesso em: 04/04/2016.

ROYO, J. Design digital. São Paulo: Rosari, 2008.

SANTAELLA, L. A estética política das mídias locativas. Nómadas, Colombia, n. 28, p. 128-137, 2008. Disponível em :

$<$ http://nomadas.ucentral.edu.co/nomadas/pdf/nomadas_28/28_12S_Aesteticapoliticada smidias.pdf $>$.

SCHULENBURG, R. R. W. Modelo conceitual de interface ergonômica para smartphone voltada ao gerenciamento de aulas pelo professor de ensino superior. Dissertação Mestrado em Design e Expressão Gráfica. Florianópolis: 2012. 137 p. Universidade Federal Santa Catarina.

SHENG, C.; CHEN, M. Tourist experience expectations: questionnaire development and text narrative analysis. International Journal of Culture, Tourism and Hospitality Research, [s. 1.], v. 7, n. 1, p. 93-104, 22 mar. 2013. Emerald. $<$ http://dx.doi.org/10.1108/17506181311301390>.

TRIPWOLF (Org.). What is tripwolf about? 2016a. Disponível em: <http://www.tripwolf.com/en/page/about>. Acesso em: 02/05/2016.

TRIPWOLF (Org.). Tripwolf - Travel Guide \& Map. 2016b. Disponível em: <https://play.google.com/store/apps/details?id=com.tripwolf\&hl=pt-br>. Acesso em: 02/05/2016.

TRIPADVISOR (Org.). Sobre o TripAdvisor. 2016a. Disponível em: <https://tripadvisor.mediaroom.com/br-about-us>. Acesso em: 02/05/2016.

TRIPADVISOR (Org.). TripAdvisor: hotéis, voos. 2016b. Disponível em: $<$ https://play.google.com/store/apps/details?id=com.tripadvisor.tripadvisor\&hl=ptBR\&referrer=utm_download_tracking=Brand_AppPage_0_10568>. Acesso em: 02/05/2016.

TUSSYADIAH, I. P.; FESENMAIER, D. R. Marketing places through first-person stories: an analysis of Pennsylvania Road tripper blog. Journal of Travel \& Tourism Marketing, 25, p. 299-311, 2008. 
VISIT KOREA (Org.). Visit Korea: Official Guide. 2016. Disponível em: $<$ https://play.google.com/store/apps/details?id=com.visitkorea.eng\&hl=pt-br>. Acesso em: 02/05/2016.

WTTC. WORLD TRAVEL AND TOURISM COUNCIL. Travel and Tourism 2011, Londres, 2011. Disponível em:

$<\mathrm{http}$ //www.wttc.org/errors/404?item=\%2fresearch\%2fannual-review $>$. Acesso em: $12 / 07 / 2015$.

\section{AGRADECIMENTO}

O presente trabalho foi realizado com o apoio da Coordenação de Aperfeiçoamento de Pessoal de Nível Superior - CAPES/Brasil com a concessão de bolsa de estudos.

Recebido em: 15-05-2017.

Aprovado em: 14-06-2017. 